\title{
A Reflection on a Trio of Dimensions in Flipped Classroom in Higher Education-A Literature-Based Study
}

\author{
Hao Yang ${ }^{1}$ \\ School of Foreign Studies, Jiangnan University, Wuxi 214000, Jiangsu, China
}

\begin{abstract}
It has been a decade since flipped classroom as a structural innovation in teaching and learning is widely applied and researched in higher education across the world. This study aims to explore, based on academic literature, three core dimensions to understanding flipped classroom: pedagogies as the inner core, interpersonal relationships as the bond and complexities involved in its evaluation.
\end{abstract}

Keywords: Flipped Classroom; Pedagogy; Active Learning; Bloom’s Taxonomy

\section{Introduction}

Classrooms have long been in the grip of a trio of difficult tensions: a paradox between teachers' centralized instruction and students' diversified learning needs; a tradeoff between teaching to the test and teaching for mastery; and a dichotomy between the instructional model in traditional schoolhouse that is increasingly losing its appeal and the easily accessible high-quality learning resources online that more effectively satisfy learners' diversified interests and higher aspirations. Left unaddressed, this trio would increasingly pull traditional classrooms to a domain of ever diminishing returns in terms of both teaching and learning.

Turning the conventionally inside teacher-led, lecture-based knowledge delivery out and the normally outside student-driven, practice-based knowledge internalization in - often with the assistance of instructional videos and web-based learning platforms, flipped classroom responds strategically to those deep tensions by addressing a simple yet profound question: "What is the best use of face-to-face time with students? (Bergmann \& Sams, 2014, p.3)".

\section{An overview of flipped classroom}

In recent years, the global higher education sector has seen an increasing uptake of flipped classroom. While the high-minded vision of cultivating students' 21 st century skills has since been recognized as the top rationale underlying the trend, it is those pragmatic concerns that most strongly motivate the practitioners on the ground-most notably, low student engagement in traditional didactic teaching, insufficient hours spent on academic pursuits on the part of students, high expectations on teachers to improve student learning outcomes, etc. The solution, as existing research shows, lies with teachers' conscientious reflection on pedagogies, cognitive objectives, student-teacher relationships, and subtleties involved in its evaluation.

\subsection{Pedagogies as the inner core}

Flipped classroom is a rich class of instructional practices that share an educational philosophy of engaging in active and higherorder learning through a reversal of the usual classroom procedure yet vary in pedagogical designs aimed at its implementation. Bergmann and Sams, the two early pioneers of flipped classroom, suggest that the flipped model is fully compatible with such pedagogical strategies as mastery learning, inquiry-based learning, universal design for learning (UDL), and even direct instruction, and recommend their integration, echoing what Christensen considered as making "the best of the old and new paradigms" (Horn \& Staker, 2014).

The educational philosophy that informs most pedagogical strategies employed in the flipped model of instruction is active learning. Bonwell and Eison (1991) characterized active learning as involving students in higher-order thinking (such as analysis, synthesis and evaluation), a variety of activities (including reading, discussing and writing) and exploration of their own attitudes and values, beyond students' usual role as a mere recipient of knowledge, opinions and skills.

The growing importance attached to this line of thinking manifests itself in the constant revisits and revisions to the Bloom's original taxonomy of educational objectives in cognitive domain from flipped classroom practitioners and researchers. Having reviewed his initial metaphorical flipping over of Bloom's taxonomy pyramid as a means of conceptual illustration of flipped

1 About the author: Hao Yang is an Associate Professor in English Language and Literature at Jiangnan University in China. His research interests include educational technology, pedagogy and computer-assisted language learning (CALL).

Copyright (C) 2020 Hao Yang

doi: 10.18282/1-e.v9i2.1405

This is an open-access article distributed under the terms of the Creative Commons Attribution Non-Commercial License

(http://creativecommons.org/licenses/by-nc/4.0/), which permits unrestricted non-commercial use, distribution, and reproduction in any medium, provided the original work is properly cited. 
classroom, Bergmann recommended that in both K-12 schools and universities classroom face-to-face time should be spent on the middle part of the taxonomy, namely applying, analyzing and evaluating, considering the impracticality of concentrating the better part of the classroom time on creating. Intrinsically, flipped classroom serves to address tensions among seemingly competing though ultimately complementary - learning objectives (Mazur, 2009; Deslauriers, Schelew \& Wieman, 2011; Wasserman, Quint, Norris \& Carr, 2017) by carving out a great proportion of in-class time for the more challenging and important one(s).

Another source from which different variants of flipped classroom arise involves structural adaptations. Amid an ongoing trend of higher education reform in China, Zhang (2014) restructured his undergraduate Research Methods in Psychology class. Although he maintained in-class both content delivery and active learning, he staggered the two components by a week. Zhang called this pedagogical approach PAD class (Presentation-Assimilation-Discussion), or halved classroom, translated literally from Chinese. The PAD model loses none of the core components of flipped classroom, yet by preserving lecture-based instruction in-class and providing more extended period for self-paced review and reflection out-of-class, it better prepares generally passive Chinese students to engage in higher-order learning activities without requiring a sudden change of habitus. If the rationale behind flipped classroom is to trade some teaching space for better use of learning time, the PAD model seeks quality time for learning without trading off the traditional teaching space still widely deemed to be an essential part of schooling.

Huang, Lai \& Wang (2015) proposed a flipped classroom model based on the notion of seamless learning, further streamlining the internal structure of the original flipped model by including what is normally considered informal learning as an integral part of the formal curriculum via networked mobile devices. This seamless flipped model introduces an in-field-learning dimension into the traditionally two-dimensional view of education as occurring only between the classroom and home learning settings, considerably expanding the learning space and activating the channels of communication among teachers and students in ways that are hitherto underutilized.

\subsection{Interpersonal relationships as a bond of learning}

A broader pattern has been emerging from years of research: to foster active learning requires teachers to take a proactive and empathic perspective towards learners.

Hattie's (2009) synthesis of meta-analyses concerning effective teaching suggests that teachers who intervene as an activator achieve a higher effect than those who serve as a mere facilitator. This is a marked contrast between an average of $\mathrm{d}=0.60$ and $\mathrm{d}=0.17$, which suggests that a proverbial shift from 'sage on the stage' to 'guide on the side' is only a halfway house leading towards truly effective teaching. The same goes for students in a parallel shift from a passive recipient through an active participant to a proactive learner.

Bergmann believes that fundamental to good teaching, regardless of pedagogy and technology employed, are human interactions. Sams, in his flipped chemistry class, immerses himself among students when he "hunker(s) down, like kids...getting messy, getting dirty with them". This approach is echoed in University of Delaware's problem-based learning workshops that train teachers to mirror the learning process of their students by putting themselves in the position of learners. This proactive and empathic role implies not just teachers' active intervention, but also their timely withdrawal. Mazur, an early pioneer of flipped model of teaching, finds that sometimes peer instruction is more effective than teacher's direct instruction in promoting understanding of difficult concepts. In hindsight but from an empathic perspective, he reasons that peer instruction enables students to probe into concepts from a novice's view, something beyond a professor who has long since cleared the cognitive barrier and for whom things are taken for granted. An empathic teacher must in turn meet his/her mirror image in empathic learners. Delozier \& Rhodes (2016), in a literature review on key ideas concerning flipped classroom, cited two empirical studies (Nestojko et al., 2014; Fiorella \& Mayer, 2014) which showed that students who learned with the expectation of teaching another student performed better in the test than those who learned in anticipation of a test, and that those who actually did teach performed best. Therefore, an interactive and dynamic relationship between teachers and students requires that, as Hattie (2009) summarizes in his model of visible teaching - visible learning, teachers see learning through the eyes of the student and students see themselves as their own teachers.

\subsection{Complexities in evaluating flipped classroom}

As flipped learning practitioners grow more adept at expanding in-class coverage of the cognitive domain, weaving a seamless learning space spanning in- and off-class hours, and cultivating more interactive and empathic learning ethos, evaluation of the effects of flipped classroom on learning would become significantly less straightforward. Student test performance is most commonly used as an indicator of the effects of flipped classroom in comparison with the traditional lecture-based approach. Results emerging from empirical studies are mixed and reveal a complex picture. While some studies (Flores, del-Arco \& Silva, 2016; Hsieh, Wu \& Marek, 2016) imply that the adoption of flipped model leads to better student test performance compared with the traditional approach, others (Yong, Levy \& Lape, 2015; McNally et, al., 2016) suggest that the jury is still out - with good reasons. In a comprehensive overview of meta-analyses on blended learning, Skrypnyk et, al. (2015) pointed to a confounding variable such as various forms of additional inputs as an explanation of apparent advantages of blended learning over the traditional learning environment in achievement gains.

Cognizant of this subtlety and the need to untangle the complexities in determining the effects of flipped classroom - namely the extent to which it is pure inversion of instruction, rather than the sheer quantity and quality of additional time, resources and efforts committed, that makes a real difference, Yong et al. (2015) had set out to run a 4-year controlled study in flipping an undergraduate introductory calculus course - controlled in the sense that researchers saw to it that learning contents, instructional resources, pedagogical orientation, student motivations, and classroom ethos remained equal in both experimental and controlled cohorts. It is particularly worth noting that in this study, an interactive lecture with elements of active learning is given to the 
controlled cohort and all student participants have generally high self-efficacy and positive attitudes about learning science and mathematics, among whom a strong culture of self-regulation, peer learning and mutual help have already been in place. The researchers reported no statistically significant effect on student achievement and attitudes due to pure flipping, speculating that contextual factors such as strong group-work culture, equal access to instructional resources and opportunities for real-time questioning during lecture may mitigate the advantages supposedly enjoyed by the flipped model. Driven by a similar desire to approximate the effect of pure flipping, Wasserman et al. (2017) held constant the total time required to complete out-of-class work by devoting an amount of in-class time - roughly equal to the associated video assigned to the flipped cohort - to addressing some of the assigned homework problems to the traditional cohort. Although researchers reported that flipped students achieved small to moderate gains over their traditionally taught counterparts, the effect sizes, when further analysis adjusted for effects of pre-test and SAT scores, become smaller.

Although there is a widespread belief in the education research community that flipped classroom has a unique structural advantages over the traditional classroom, evidence suggests that flipped model may not exert as powerful an effect on student performance in standardized exams as some studies (Flores, del-Arco \& Silva, 2016; Hsieh, Wu \& Marek, 2016) suggest when controlled for commitment of time and resources.

\section{Conclusion}

While students' test performance and their personal preferences are often tacitly assumed to be the most salient criteria in justifying the use of flipped classroom, research suggests that use of flipped classrooms is not causally and positively related to them, nor are they reliable predictors of each other. On the one hand, evidence is inconclusive as to the advantage of flipped over traditional lecture-based instructions in terms of test results; on the other hand, it is active learners and active learning style of instruction - not flipping per se - that are identified as the key to making successful flipped classrooms. Thus, the true value of flipped classroom lies with the pedagogical space it affords in which active learning is better positioned to occur and therefore, flipped classroom research should now shift its attention towards exploring enabling conditions for students' adaptation to active learning rather than stay focused on a debate over relative merits of flipped versus traditional instructions that becomes increasingly irrelevant.

\section{Acknowledgements}

This work was supported by Ministry of Education of China under the Philosophy \& Social Sciences Prosperity in Higher Education Institution Program [grant number 15YJC880106] and by Jiangnan University under the On-line Course Development Program [grant number 2020ZJ24].

\section{References}

1. Bergmann, J., \& Sams, A. (2014). Flipped Learning: Gateway to Student Engagement. Eugene, OR: International Society for Technology in Education.

2. Bonwell, C., \& Eison, J. (1991). Active learning: Creating excitement in the classroom. ASHE-ERIC Higher Education Report No. 1. Washington, DC: George Washington University. Full Text: http://files.eric.ed.gov/fulltext/ED336049.pdf

3. Delozier, S. J., \& Rhodes, M. G. (2017). Flipped Classroom: a Review of Key Ideas and Recommendations for Practice. Educational Psychology Review, 29(1), 141-151.

4. Deslauriers, L., Schelew, E., \& Wieman, C (2011). Improved Learning in a Large-Enrollment Physics Class. Science, 332 (6031), 862-864.

5. Flores, Ò., del-Arco, I., \& Silva, P. (2016). The flipped classroom model at the university: analysis based on professors' and students' assessment in the educational field. International Journal of Educational Technology in Higher Education, 13 (21).

6. Hattie, J. (2009). Visible Learning: A Synthesis of over 800 Meta-analyses Relating to Achievement. Oxford: Routledge.

7. Hsieh, J. S. C., Wu, W. C. V., \& Marek, M. W. (2016). Using the flipped classroom to enhance EFL learning. Computer Assisted Language Learning. 30 (1-2), 1-21.

8. Horn, M., \& Staker, H. (2014) Blended: Using Disruptive Innovation to Improve Schools. San Francisco, CA: Jossey-Bass.

9. Huwang, G. J., Lai, C. L., \& Wang, S. Y. (2015). Seamless flipped learning: a mobile technology-enhanced flipped classroom with effective learning strategies. Journal of Computers in Education, 2 (4), 449-473.

10. Mazur, E. (2009). Farewell, Lecture?. Science, 323 (5910), 50-51.

11. McNally, B., Chipperfield, J., Dorsett, P., Del Fabbro, L., Frommolt, V., Goets, S., Lewohl, J., Molineux, M., Pearson, A., Reddan, G., Roiko, A., \& Rung, A. (2016). Flipped classroom experiences: student preferences and flip strategy in a higher education context. Higher Education, 73(2), 281-298.

12. Skrypnyk, O., Joksimovic, S., Kovanovic, V., Dawson, S., Gasevic, D., \& Siemens, G. (2015). The History and State of Blended Learning. In. G. Siemens, D.

13. Gasevic, \& S. Dawson (Eds.), Preparing for the digital university: a review of the history and current state of distance, blended, and online learning (pp. 55-92) [Online Publication]. Retrieved from http://linkresearchlab.org/PreparingDigitalUniversity.pdf

14. Wasserman, N. H., Quint, C., Norris, S. A., \& Carr, T. (2017). Exploring Flipped Classroom Instruction in Calculus III. International Journal of Science and Mathematics Education, 15, 545-568.

15. Yong, D., Levy, R., \& Lape, N. (2015). Why no difference? A controlled flipped classroom study for an introductory differential equations course. PRIMUS, 25 (9-10), 907-921.

16. Zhang, X. X. (2014). PAD class: A new attempt in university teaching reform. Fudan Education Forum, 12(5), 5-10. 